\title{
Quantification of the total ion transport in the near-Earth plasma sheet
}

\author{
Rikard Slapak $^{1}$, Maria Hamrin ${ }^{2}$, Timo Pitkänen ${ }^{2}$, Masatoshi Yamauchi ${ }^{3}$, Hans Nilsson ${ }^{1,3}$, Tomas Karlsson ${ }^{4}$, and \\ Audrey Schillings ${ }^{1,3}$ \\ ${ }^{1}$ Division of Space Technology, Luleå University of Technology, Kiruna, Sweden \\ ${ }^{2}$ Department of Physics, Umeå University, Umeå, Sweden \\ ${ }^{3}$ Swedish Institute of Space Physics, Kiruna, Sweden \\ ${ }^{4}$ Space and Plasma Physics, School of Electrical Engineering, Royal Institute of Technology, Stockholm, Sweden \\ Correspondence to: Rikard Slapak (rikard.slapak@1tu.se)
}

Received: 14 March 2017 - Revised: 6 June 2017 - Accepted: 9 June 2017 - Published: 26 July 2017

\begin{abstract}
Recent studies strongly suggest that a majority of the observed $\mathrm{O}^{+}$cusp outflows will eventually escape into the solar wind, rather than be transported to the plasma sheet. Therefore, an investigation of plasma sheet flows will add to these studies and give a more complete picture of magnetospheric ion dynamics. Specifically, it will provide a greater understanding of atmospheric loss. We have used Cluster spacecraft 4 to quantify the $\mathrm{H}^{+}$and $\mathrm{O}^{+}$total transports in the near-Earth plasma sheet, using data covering 2001-2005. The results show that both $\mathrm{H}^{+}$and $\mathrm{O}^{+}$have earthward net fluxes of the orders of $10^{26}$ and $10^{24} \mathrm{~s}^{-1}$, respectively. The $\mathrm{O}^{+}$plasma sheet return flux is 1 order of magnitude smaller than the $\mathrm{O}^{+}$outflows observed in the cusps, strengthening the view that most ionospheric $\mathrm{O}^{+}$outflows do escape. The $\mathrm{H}^{+}$return flux is approximately the same as the ionospheric outflow, suggesting a stable budget of $\mathrm{H}^{+}$in the magnetosphere. However, low-energy $\mathrm{H}^{+}$, not detectable by the ion spectrometer, is not considered in our study, leaving the complete magnetospheric $\mathrm{H}^{+}$circulation an open question. Studying tailward flows separately reveals a total tailward $\mathrm{O}^{+}$flux of about $0.5 \times 10^{25} \mathrm{~s}^{-1}$, which can be considered as a lower limit of the nightside auroral region $\mathrm{O}^{+}$outflow. Lower velocity flows $\left(<100 \mathrm{~km} \mathrm{~s}^{-1}\right)$ contribute most to the total transports, whereas the high-velocity flows contribute very little, suggesting that bursty bulk flows are not dominant in plasma sheet mass transport.
\end{abstract}

Keywords. Magnetospheric physics (magnetospheric configuration and dynamics; plasma sheet)

\section{Introduction}

Studies of ion dynamics and circulation in the terrestrial magnetosphere are important for the understanding of atmospheric escape, and consequently for the atmospheric evolution at Earth. Ions of ionospheric origin continuously flow out into the terrestrial magnetosphere (e.g. Shelley et al., 1982 and Chappell et al., 2000), where they are governed by the geomagnetic field. The high-latitude polar regions, associated with open field lines, are the regions subject to most ion outflow. These regions, including the cusps, facilitate conditions for upflowing ionospheric ions to be put on trajectories along field lines directly connected to the magnetosheath/solar wind. The fate of this outflow depends mainly on its interaction with plasma waves and how effectively the ions are energised along their trajectories (Nilsson et al., 2012). The auroral regions, on the other hand, are magnetically connected to the closed plasma sheet field lines, and consequently ionospheric outflow associated with the auroral region is an additional source for plasma sheet ions. A review of ion outflow in the polar region is given by Yau and André (1997), where different types of ion outflows in different parts of the polar region are discussed and summarised.

Ionospheric outflow in the cusp - subject to intense magnetosheath inflow and strong wave activity - is the dominant source of $\mathrm{O}^{+}$in the magnetosphere (Dubouloz et al., 2001), with typical total fluxes of $2 \times 10^{25} \mathrm{~s}^{-1}$ (Pollock et al., 1990). Recent studies show that a majority of this outflow will escape, either directly from the cusp (Slapak et al., 2013) or in the distant tail via the plasma mantle 
(Nilsson, 2011; Nilsson et al., 2012). If not sufficiently energised, the ions will convect to the plasma sheet. Previous works report observations of $\mathrm{O}^{+}$seen as cold beams (narrow velocity distributions) in the lobes (Orsini et al., 1990; Seki et al., 1998; Liao et al., 2010), and $\mathrm{O}^{+}$feed from the lobes (Orsini et al., 1990; Liao et al., 2012, 2015). The plasma sheet is also fed with $\mathrm{H}^{+}$from the lobes, but $\mathrm{H}^{+}$may originate either from the polar open ionospheric region or from the solar wind/magnetosheath, entering via the dayside cusps. As opposed to $\mathrm{O}^{+}$, the ionospheric $\mathrm{H}^{+}$outflow is significant over the whole polar cap, the phenomenon which is referred to as the polar wind, coined by Axford (1968). Engwall et al. (2009b) showed that the polar wind is dominated by low-energy protons, with energies typically too low to be detected by ion spectrometers. However, a technique considering electric field measurements in the wake behind an electrically charged spacecraft allows for detection of these low-energy ions (Engwall et al., 2006). This technique was used by Engwall et al. (2009a) and André and Cully (2012), who showed that the total polar $\mathrm{H}^{+}$ionospheric outflow is of the order of $10^{26} \mathrm{~s}^{-1} . \mathrm{H}^{+}$feed from the lobes to the plasma sheet has been presented and discussed in several studies, e.g. Cully et al. (2003) and Haaland et al. (2012). $\mathrm{O}^{+}-$with a 16 times higher mass than protons - typically has energies larger than the spacecraft potential (Engwall et al., 2009a). Also, Nilsson et al. (2010) concluded that $\mathrm{O}^{+}$reaches observable energies due to centrifugal acceleration in the lobes, and we do not need to worry about a "hidden" low-energy $\mathrm{O}^{+}$population.

Ion transport in the plasma sheet is expected to primarily be in the earthward direction and generally driven by the global magnetospheric dawn-dusk convection electric field. Ejiri et al. (1980) showed that a uniform dawn-dusk electric field is not consistent with data, but a so-called VollandStern-type electric field, which increases with increased geomagnetic activity, better describes the earthward plasma convection.

In addition to steady earthward convection, there are observations of high-speed $\mathrm{H}^{+}$flows as well, both tailward and earthward, which appear as isolated events (in time and space) (Lui et al., 1983; Baumjohann et al., 1990; Angelopoulos et al., 1992), and usually referred to as bursty bulk flows (BBFs). In the near-Earth plasma sheet these highspeed flows are most frequently directed earthward, as a consequence of tail reconnection events (Sharma et al., 2008, and references therein) and the associated $\boldsymbol{j} \times \boldsymbol{B}$ force on the closed but stretched field lines. Acceleration and braking of BBFs in the near-Earth plasma sheet have been presented and discussed by, for example, Hamrin et al. (2014) and Karlsson et al. (2015).

BBFs have been reported to contribute significantly and even dominate the transport of energy, mass, and magnetic flux (Angelopoulos et al., 1994, 1999). However, contradicting results have been presented, as results presented by Paterson et al. (1998) suggest that BBFs do not contribute much to the total transport of magnetic flux. $\mathrm{O}^{+}$ions associated with BBFs has been shown to be magnetically decoupled from the $\mathrm{H}^{+}$and have only a very small increase in velocity in comparison with the protons (Nilsson et al., 2016). Therefore, we would not expect BBFs to be important or a significant contributor to the total $\mathrm{O}^{+}$in the plasma sheet. De Spiegeleer et al. (2017) found that there is oscillatory plasma motions in the plasma sheet, often of intermittent flow speeds, which occurs more frequently than high-speed flows, at least during low and moderate geomagnetic activity.

In this paper, we will quantify the total $\mathrm{H}^{+}$and $\mathrm{O}^{+}$transport in the plasma sheet in order to complement earlier studies of ion outflow in the polar regions and ion escape into the solar wind. A quantification of the plasma sheet transport will increase the understanding of auroral zone outflow and ion feed to the plasma sheet from the lobes. Observed $\mathrm{H}^{+}$ origins either from the Earth's atmosphere or the solar wind, and the different populations are often difficult to distinguish. Therefore, transport of $\mathrm{O}^{+}-$which is of atmospheric origin in the plasma sheet is of specific interest since it will complement studies of $\mathrm{O}^{+}$outflow and escape in terms of magnetospheric ion circulation in general and atmospheric evolution specifically.

\section{Data}

In this section we give a brief description of the instrument used in this study, onboard the Cluster spacecraft (Escoubet et al., 2001), covering 2001-2005, as well as present the criteria used for the plasma sheet ion data.

\subsection{Instruments}

The Cluster spacecraft are four satellites flying in formation, each with an identical set of 11 instruments. In this paper the focus is on ion flows on large scales and we will therefore use data only from one spacecraft. Data obtained by the Composition Distribution Function (CODIF) spectrometer, described in detail by Rème et al. (2001), will be used. Both Cluster 1 and Cluster 4 - with well-working CODIF instruments - are suitable, and we will consider Cluster 4 data, as this spacecraft is used in our earlier statistical ion flow studies. CODIF uses a time-of-flight technique allowing for ion mass resolution and provides ion distributions (for particle energies between $15 \mathrm{eV}$ and $38 \mathrm{keV}$ for singly charged ions) from which the ion moments have been determined. In this study, we use data with a time resolution of $4 \mathrm{~s}$ (the spacecraft spin period).

\subsection{Data selection criteria}

The plasma sheet is a region of the magnetotail that is considerably hotter and denser and with weaker magnetic field strengths than the adjacent tail lobes. Therefore, the plasma $\beta$ parameter, defined as the ratio between the thermal and mag- 

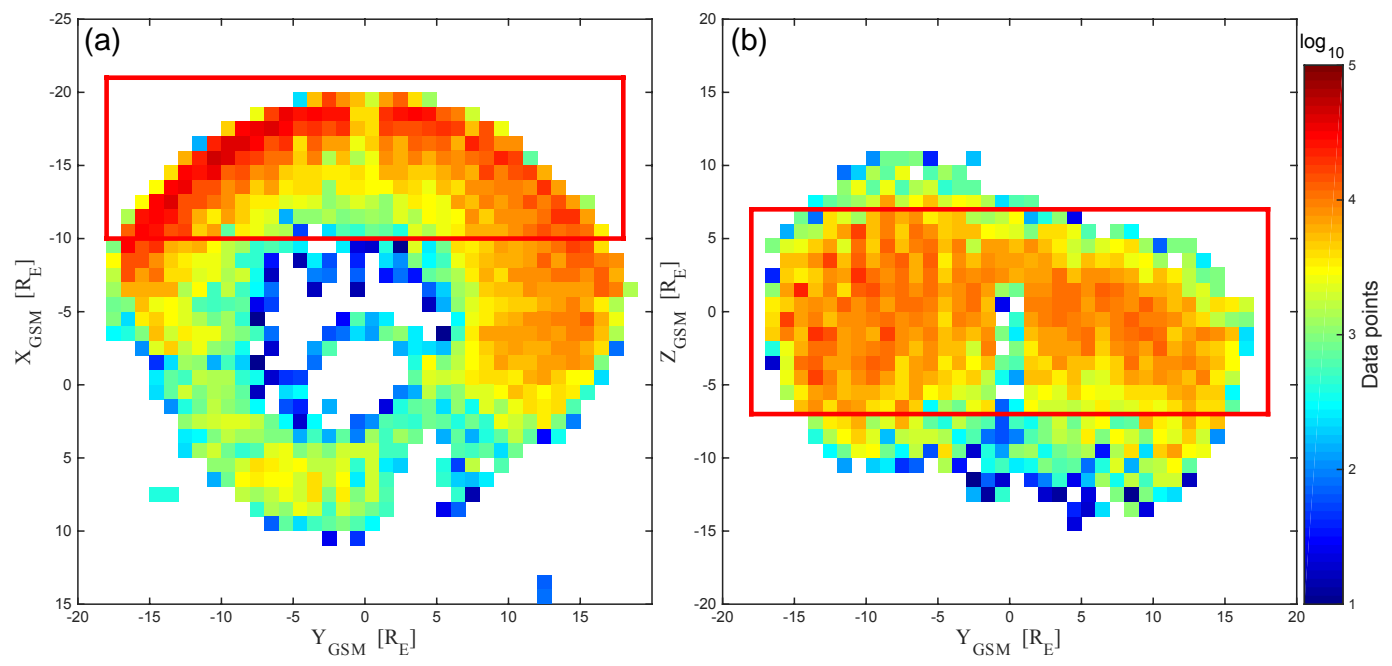

Figure 1. Spatial coverage of data points (2001-2005) that meet the plasma sheet criteria as described in Sect. 2.2 projected to the $\left.X Y\right|_{\mathrm{GSM}}$ plane (a), for which data with $\left|Z_{\mathrm{GSM}}\right|<7 R_{\mathrm{E}}$ have been excluded, and to the $\left.Y Z\right|_{\mathrm{GSM}}$ plane (b), for which data with $X_{\mathrm{GSM}}>-10 R_{\mathrm{E}}$ have been excluded. The number of data points is given by the colour as defined in the bar to the right. The data included in the plasma sheet ion transport study are within the red rectangles.

netic pressure, is an efficient - and commonly used - parameter for separating plasma sheet data (higher $\beta$ ) from lobe data (low $\beta$ ). We use the restriction $\beta>1$ for the central plasma sheet, and $0.1<\beta<1$ for the outer plasma sheet (Baumjohann et al., 1988, 1989; Kistler et al., 2006). The outer plasma sheet is more or less equivalent to the plasma sheet boundary layer (PSBL), a layer adjacent to the open/closed field-line boundary. The PSBL/outer plasma sheet maps to the poleward part of the auroral oval and it separates the open polar cap magnetic field lines from the central plasma sheet field lines in the equatorward part of the auroral oval in the ionosphere.

The spatial coverage of the Cluster satellites during 20012005 is illustrated in Fig. 1, given in the $\left.X Y\right|_{\text {GSM }}$ (only $\left|Z_{\mathrm{GSM}}\right|<7 R_{\mathrm{E}}$ included) and $\left.Y Z\right|_{\mathrm{GSM}}$ planes (only $X_{\mathrm{GSM}}<$ $-10 R_{\mathrm{E}}$ included), where the numbers of data points in $1 R_{\mathrm{E}} \times 1 R_{\mathrm{E}}$ bins are shown and defined by the colour scale. We limit our statistical study to data within $-20<X_{\mathrm{GSM}}<$ $-10 R_{\mathrm{E}}$ and $-7<Z_{\mathrm{GSM}}<7 R_{\mathrm{E}}$, as illustrated by the red boxes in Fig. 1. We have removed data where there is contamination in the CODIF $\mathrm{O}^{+}$channel in order to exclude magnetosheath data (also high $\beta$ ). For heavily contaminated $\mathrm{O}^{+}$channels there is a peak at $1 / 4$ for the $\mathrm{O}^{+}$over $\mathrm{H}^{+}$perpendicular bulk flow ratio, due to the 16 times higher mass of $\mathrm{O}^{+}$, and the data are consequently removed (Nilsson et al., 2006). We have also used an additional constraint to remove magnetosheath data: $T_{\perp} / n>1000 \mathrm{eV} \mathrm{cm}^{-3}$, where $T_{\perp}$ and $n$ are the $\mathrm{H}^{+}$perpendicular temperature and density, respectively (Hamrin et al., 2009). For the $\mathrm{H}^{+}$density the requirement is $10^{-3}<n_{\mathrm{H}^{+}}<10 \mathrm{~cm}^{-3}$. The lower density limit is to ensure that the bulk velocity estimates are reliable, and the upper limit will remove a set of extreme outliers. We set the same limits on the $\mathrm{O}^{+}$density within the plasma sheet data set for the same reasons.

\section{Observations}

We will estimate the total ion transport in the plasma sheet in the earthward and tailward direction. First, we will not distinguish between steady background convection (with adiabatic energisation) and high-velocity flows but instead investigate all data. Then we will follow by deriving the contributions from different velocity ranges by binning the data with respect to velocity. We will calculate the total transport by considering the $X_{\mathrm{GSM}}$ component of the average local ion fluxes through the $\left.Y Z\right|_{\mathrm{GSM}}$ plane. In order to do so, we project plasma sheet data (as defined in Sect. 2.2) to the $\left.Y Z\right|_{\mathrm{GSM}}$ plane and divide the data into $1 R_{\mathrm{E}} \times 1 R_{\mathrm{E}}$ bins, such that each bin corresponds to a "quadratic column". In addition, we divide the data into earthward flow and tailward flow and treat them separately for both ion species of consideration. For each bin (or column) we calculate the corresponding average ion earthward and tailward flux. The central plasma sheet results are shown in the top panels of Figs. $2\left(\mathrm{H}^{+}\right)$and 3 $\left(\mathrm{O}^{+}\right)$, as defined by the colour bars (note that the colour scales are different for the two species). In the middle panels the corresponding bin-wise occurrence rates are presented, given by the colour scale in percentage. The $\mathrm{H}^{+}$occurrence rate for a given bin is defined as the number of data points in that bin fulfilling the plasma sheet selection criteria and flowing earthward and tailward, respectively, divided by the total number of data points (both plasma sheet data and data not fulfilling the plasma sheet criteria) in the same bin. Multiplying the occurrence rates by the local average fluxes gives the 

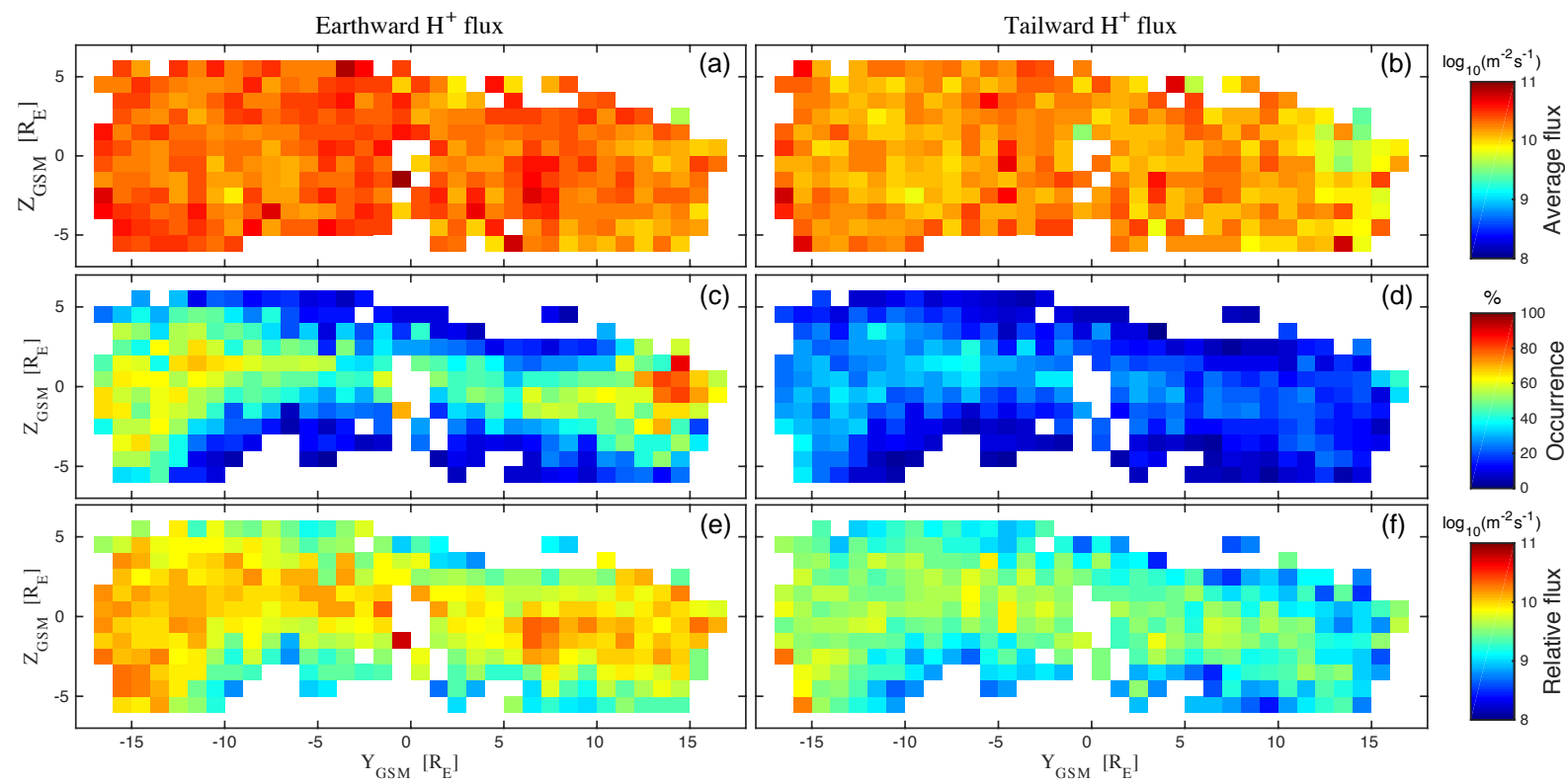

Figure 2. The spatial distributions (given in $R_{\mathrm{E}}^{2}$ square bins) projected to the $\left.Y Z\right|_{\mathrm{GSM}}$ for earthward (a, c, e) and tailward (b, d, f) central plasma sheet $\mathrm{H}^{+}$fluxes. $(\mathbf{a}, \mathbf{b})$ Average local fluxes; $(\mathbf{c}, \mathbf{d})$ occurrence rates; $(\mathbf{e}, \mathbf{f})$ the time-average fluxes obtained by multiplying the average flux by the occurrence frequency bin by bin.

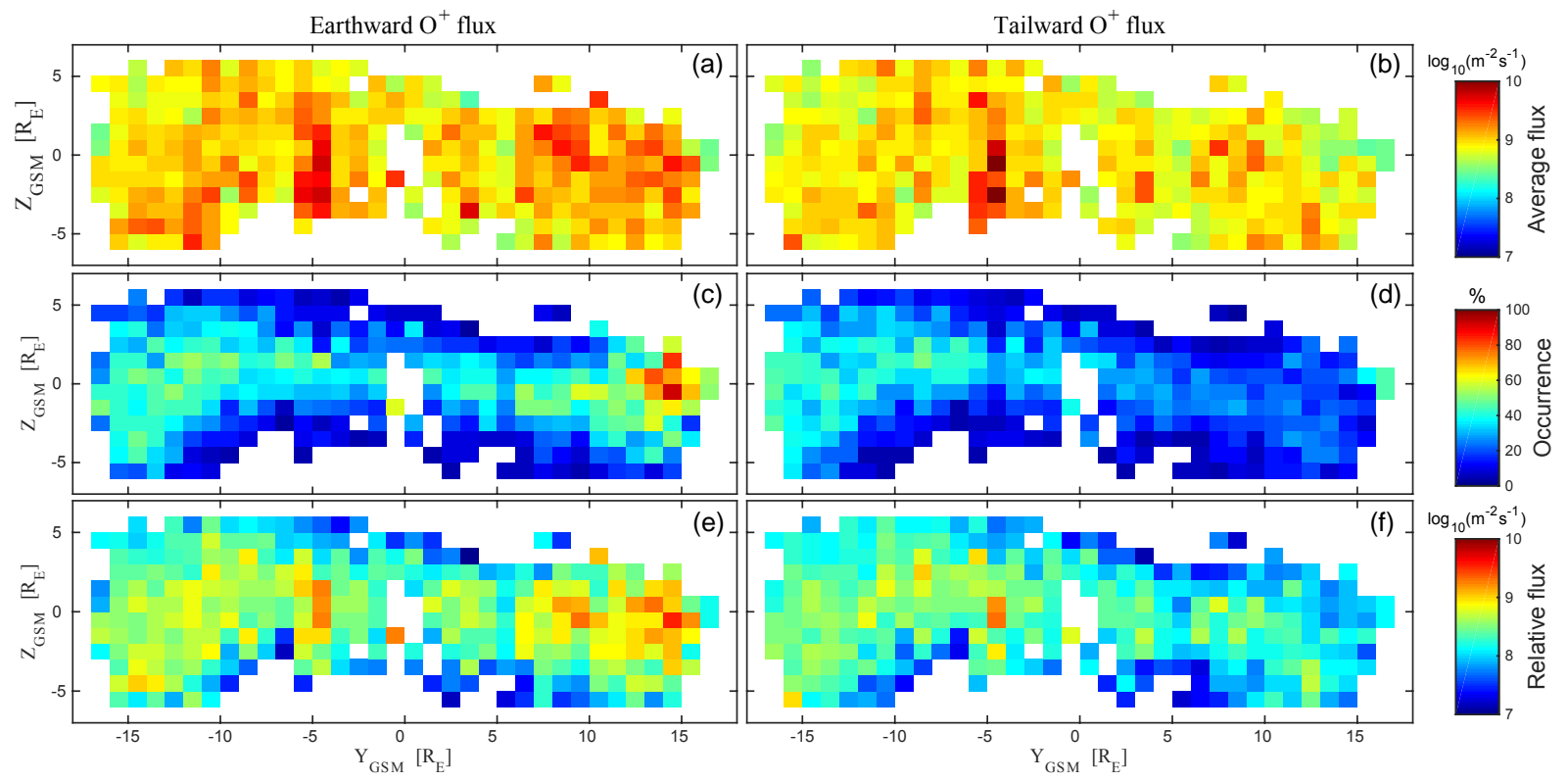

Figure 3. The spatial distributions of central plasma sheet $\mathrm{O}^{+}$fluxes. It is the same format as in Fig. 2, but note the different colour scale.

time-average flux for each bin (bottom panels). Each timeaverage flux can equivalently be considered as a continuous stream of ions, and therefore multiplying this time-average flux with the bin area in the $\left.Y Z\right|_{\mathrm{GSM}}$ plane $\left(1 R_{\mathrm{E}}^{2}\right)$ will give a total flux corresponding to that bin. The total earthward (or tailward) flux is then obtained by integrating over all bins.

The obtained total fluxes for $\mathrm{H}^{+}$and $\mathrm{O}^{+}$ions are summarised in Table 1, for both the central plasma sheet and the outer plasma sheet (calculated in the same manner). Both ion species have larger earthward than tailward total fluxes in the central plasma sheet, and consequently the net fluxes are directed earthward in this region. The $\mathrm{H}^{+}$and $\mathrm{O}^{+}$net fluxes are $5.5 \times 10^{25} \mathrm{~s}^{-1}$ and $2.2 \times 10^{24} \mathrm{~s}^{-1}$, respectively. The outer plasma sheet has fluxes of the same order of magnitude, and $\mathrm{H}^{+}$has a net earthward flux of $2.3 \times 10^{25} \mathrm{~s}^{-1}$ in that region. $\mathrm{O}^{+}$, on the other hand, is typically observed to flow in the op- 
Table 1. Summary of calculated total $\mathrm{H}^{+}$and $\mathrm{O}^{+}$transports $\left(\mathrm{s}^{-1}\right)$ in the near-Earth plasma sheet $\left(-20<X_{\mathrm{GSM}}<-10 R_{\mathrm{E}}\right)$. The transports are given separately for earthward, tailward flows, and the corresponding net fluxes, for the central plasma sheet, outer plasma sheet, and the whole plasma sheet.

\begin{tabular}{lrr|rr|rr}
\hline & \multicolumn{5}{c}{ Ion transport $\left(\mathrm{s}^{-1}\right)$} \\
\hline Region & \multicolumn{2}{c}{ Central plasma sheet } & \multicolumn{2}{c}{ Outer plasma sheet } & \multicolumn{2}{|}{$\begin{array}{r}\text { Whole plasma sheet } \\
\mathrm{H}^{+}\end{array}$} \\
Ion species & $\mathrm{H}^{+}$ & $\mathrm{O}^{+}$ & $\mathrm{H}^{+}$ & $\mathrm{O}^{+}$ & $\mathrm{O}^{+}$ \\
\hline Earthward & $8.3 \times 10^{25}$ & $4.6 \times 10^{24}$ & $4.6 \times 10^{25}$ & $1.1 \times 10^{24}$ & $1.3 \times 10^{26}$ & $5.7 \times 10^{24}$ \\
Tailward & $-2.8 \times 10^{25}$ & $-2.4 \times 10^{24}$ & $-2.2 \times 10^{25}$ & $-2.2 \times 10^{24}$ & $-5.0 \times 10^{25}$ & $-4.6 \times 10^{24}$ \\
Net total flux & $5.5 \times 10^{25}$ & $2.2 \times 10^{24}$ & $2.3 \times 10^{25}$ & $-1.1 \times 10^{24}$ & $7.8 \times 10^{25}$ & $1.1 \times 10^{24}$ \\
\hline
\end{tabular}
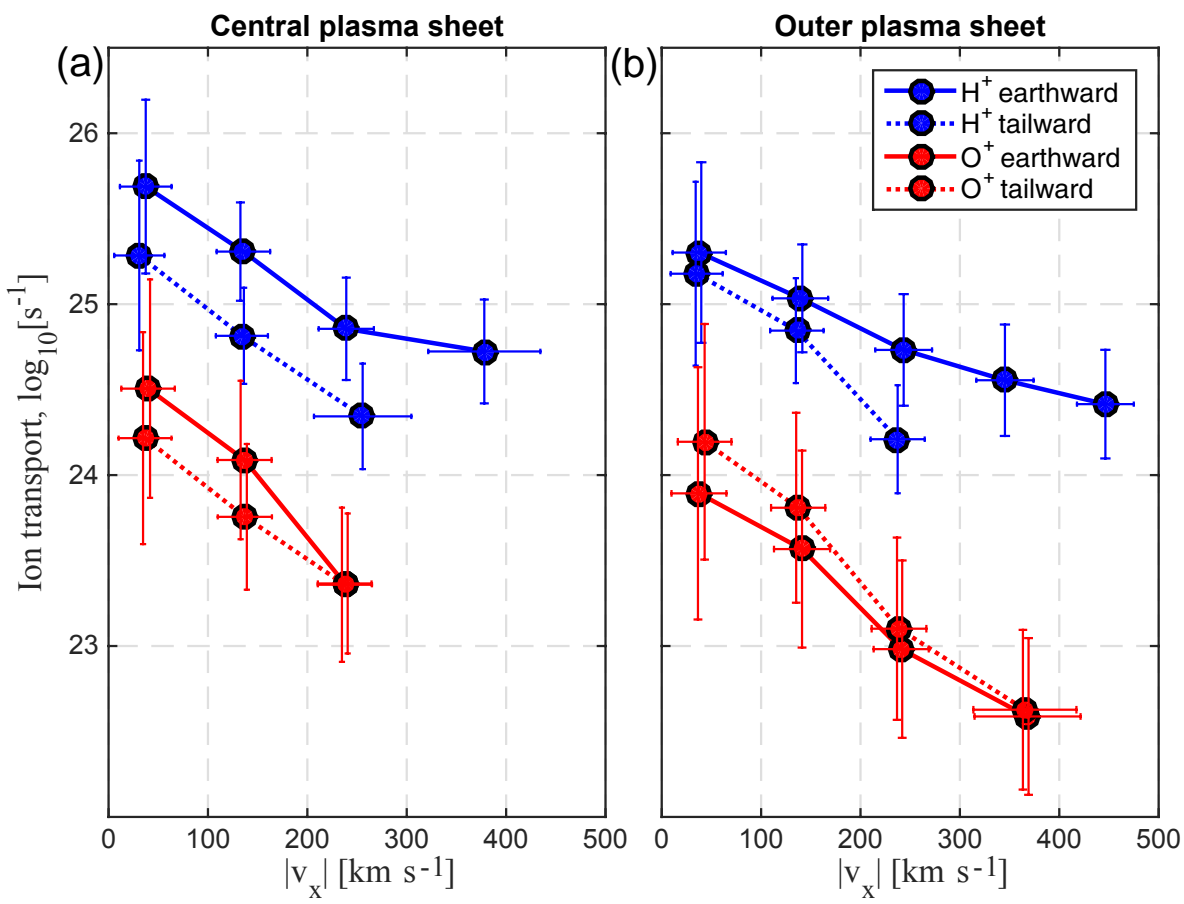

Figure 4. The estimated $\mathrm{H}^{+}$(blue) and $\mathrm{O}^{+}$(red) ion transport in the near-Earth plasma sheet, shown for earthward (solid line) and tailward (dotted line) flows separately, obtained for different $v_{x}$ intervals. The intervals are preliminarily chosen to have a width of $100 \mathrm{~km} \mathrm{~s}^{-1}$ but have been extended to $200 \mathrm{~km} \mathrm{~s}^{-1}$ a few times in order to include at least 10000 data points. The total fluxes are plotted against the average $v_{x}$ of the corresponding intervals, and the horizontal bars are the corresponding $v_{x}$ standard deviations. The vertical bars reflect the standard deviations of the local fluxes used in each corresponding total transport calculation.

posite direction and has a net tailward flux of $1.1 \times 10^{24} \mathrm{~s}^{-1}$ in the outer plasma sheet.

Next we investigate the total ion transports as functions of velocity. We divide the data into subsets of $v_{x}$ intervals with widths of $100 \mathrm{~km} \mathrm{~s}^{-1}$, except for some of the highest $v_{x}$ values, where we increased the interval width $-[300,500]$ and $[200,400] \mathrm{km} \mathrm{s}^{-1}$ in the central plasma sheet for earthward and tailward $\mathrm{H}^{+}$flows, respectively, and $[300,500] \mathrm{km} \mathrm{s}^{-1}$ in the outer plasma sheet for both earthward and tailward $\mathrm{O}^{+}$ flows - in order to have sufficient data points in each subset to perform the total transport estimate in the same manner as before. The result of these estimates is shown in Fig. 4 (left: central plasma sheet; right: outer plasma sheet), where blue and red lines correspond to $\mathrm{H}^{+}$and $\mathrm{O}^{+}$, respectively. In addition, solid and dotted lines correspond to earthward and tailward flows, respectively. The horizontal error bars are the $v_{x}$ standard deviations for each considered interval. The vertical bars reflect the standard deviations of the local fluxes for each considered $v_{x}$ interval and its corresponding total cross section. A few of the bars have been shifted slightly for visibility.

For the central plasma sheet, the result shows clearly for a given absolute interval and species - that the earthward ion transport is larger than the tailward transport, except for the highest $\mathrm{O}^{+}$velocities, where the earthward and tailward transports practically become equal. We also note that low- 
velocity flows $\left(<100 \mathrm{~km} \mathrm{~s}^{-1}\right)$ dominate the total ion transport for both species. The contribution from high-velocity flows is about 1 order of magnitude smaller than the contribution from the lower velocity flows.

Also in the outer plasma sheet the low-velocity flows dominate over the highest velocity flows in terms of ion transport. However, as already noted above, the $\mathrm{O}^{+}$tailward fluxes are higher than the earthward fluxes, and this can be seen in all considered velocity intervals.

\section{Discussion}

We have quantified the total net transport of $\mathrm{H}^{+}$and $\mathrm{O}^{+}$in the near-Earth plasma sheet, as well as the earthward and tailward transports separately, for both the central $(\beta>1)$ and the outer plasma sheet $(0.1<\beta<1)$. The estimated numbers are listed in Table 1. The net transport in the whole plasma sheet (including both central and outer plasma sheet) for both species is earthward as would be expected in the near-Earth plasma sheet if the tail reconnection point most often is located tailward of the spacecraft position. The earthward $\mathrm{H}^{+}$transport is $\sim 10^{26} \mathrm{~s}^{-1}$, which is of the same order as the polar-region-originated low-energy ionospheric outflow measured in the lobes by, for example, Engwall et al. (2009a), André and Cully (2012), and Haaland et al. (2015). However, the solar wind $\mathrm{H}^{+}$entry into the magnetosphere mainly through the cusps is of the order of $10^{27} \mathrm{~s}^{-1}$ (Savin et al., 1999; Walker et al., 2013). This influx will mirror at lower altitudes and fill the plasma mantle with high-temperature $(>1 \mathrm{keV}) \mathrm{H}^{+}$populations (Nilsson et al., 2012). The plasma mantle $\mathrm{H}^{+}$flux can be shown to also be of the order of $10^{27} \mathrm{~s}^{-1}$, using the same method as Slapak et al. (2013) did when calculating the total ion flux in the high-latitude dayside magnetosheath. These numbers therefore suggest that an $\mathrm{H}^{+}$amount about the same as the solar wind input and plasma mantle flux will escape, and that an amount about the same as the low-energy ionospheric outflow will be brought back towards Earth in the plasma sheet. Even though we cannot say for certain how large fractions of the solar wind origin $\mathrm{H}^{+}$and the ionospheric $\mathrm{H}^{+}$outflow that end up in the plasma sheet or escape, there seems to be a fairly stable budget of $\mathrm{H}^{+}$in the magnetosphere. This is, however, an open question and not in the scope of this study.

We must however note that low-energy $\mathrm{H}^{+}$is not measured and considered in our study. Seki et al. (2003) detected low-energy ions during a solar eclipse and showed that the density was approximately the same as for higherenergy ions (above the spacecraft potential). These ions are most probably $\mathrm{H}^{+}$dominated, since we do not expect "hidden" $\mathrm{O}^{+}$populations in the plasma sheet, just as there are no "hidden" low-energy populations of $\mathrm{O}^{+}$in the lobes (Engwall et al., 2009a). Therefore, one can expect the contribution from low-energy $\mathrm{H}^{+}$to the total transport to be smaller than from the measured $\mathrm{H}^{+}$, due to their lower velocities.
As opposed to $\mathrm{H}^{+}$, there does not seem to be a stable circulation of $\mathrm{O}^{+}$. The $\mathrm{O}^{+}$return flow in the plasma sheet is about 1 order of magnitude smaller than the $\mathrm{O}^{+}$ionospheric outflow. With no $\mathrm{O}^{+}$of solar wind origin to consider, this strongly suggests that a majority of the observed cusp outflows of $2 \times 10^{25} \mathrm{~s}^{-1}$ (Pollock et al., 1990) indeed will escape as has been suggested by Nilsson et al. (2012) and Slapak et al. (2013, 2015). This is in contrast to Seki et al. (2001), who observed a decrease in lobe $\mathrm{O}^{+}$flows and interpreted that as a continuous feed of $\mathrm{O}^{+}$into the plasma sheet, and did not consider any escape through the magnetopause along open field lines. They estimated the total $\mathrm{O}^{+}$flux in the nearEarth lobe tail $\left(0-75 R_{\mathrm{E}}\right)$ to be $1.8 \times 10^{24} \mathrm{~s}^{-1}, 1$ order of magnitude smaller than the typical cusp $\mathrm{O}^{+}$outflow, which then would lead to a plasma sheet return flux of the order of $10^{25} \mathrm{~s}^{-1}$ if the lobe content was fed into the plasma sheet, as they suggested. That is - as we have shown here - not the case, but most outflowing atmospheric $\mathrm{O}^{+}$will indeed escape.

The strongest earthward fluxes are seen in the central plasma sheet, by a factor of 2 and 4 higher than in the outer plasma sheet for $\mathrm{H}^{+}$and $\mathrm{O}^{+}$, respectively (Table 1). However, the $\mathrm{O}^{+}$tailward fluxes are about the same in both the central and outer plasma sheet, such that the $\mathrm{O}^{+}$net flow is tailward in the outer plasma sheet. Ionospheric outflow in the nightside auroral regions is magnetically connected to the outer plasma sheet, but this outflow takes significant time to reach our observation region, and because of the convection towards the neutral current sheet these tailward flows must correspond to lobe beams entering the plasma sheet. However, parts of the tailward fluxes in the inner plasma sheet can be of nightside ionospheric origin. The total observed tailward $\mathrm{O}^{+}$transport is $4.6 \times 10^{24} \mathrm{~s}^{-1}$, which is a factor of 2 or 3 smaller than the auroral outflow estimated by Abe et al. (1996), using Akebono/SMS at an altitude of around $1 R_{\mathrm{E}}$. However, they integrated over $60-75^{\circ}$ invariant latitude, which could explain the higher rates, because a significant part will never reach the distances of our observations.

High-velocity BBFs have been suggested to dominate the mass transport in the plasma sheet (Angelopoulos et al., 1994). In order to pick out BBFs from the data set we apply a set of constrains to be fulfilled for an event to be defined as a BBF: increased velocity $\left(>100 \mathrm{~km} \mathrm{~s}^{-1}\right)$ in the $X_{\mathrm{GSM}}$ direction in a continuous series of at least five consecutive points of measurements, and at least one measurement with a velocity $>200 \mathrm{~km} \mathrm{~s}^{-1}$. This is very similar to the conditions required by Nilsson et al. (2016). We use the same method as before for determining the total ion transport associated with these BBFs. The amount of data corresponding to BBFs is much less than the lower-speed flows: typically 100-200 data points in a spatial bin, as compared to $>1000$ data points in each bin for lower-velocity flows. However, there are still enough data points for earthward BBFs to have a good spatial coverage in the $\left.Y Z\right|_{\mathrm{GSM}}$ plane (not shown) and to estimate a total ion transport. The average $\mathrm{H}^{+}$fluxes 
are higher for BBFs, but the significantly reduced number of data points also leads to significantly smaller occurrence rates for fluxes related to BBFs. The BBF contribution to the total $\mathrm{H}^{+}$earthward transport is small: $6 \times 10^{24} \mathrm{~s}^{-1}$, and the corresponding $\mathrm{O}^{+}$transport is $7 \times 10^{22} \mathrm{~s}^{-1}$. These numbers correspond to 5 and $1 \%$ of the total earthward transport of $\mathrm{H}^{+}$and $\mathrm{O}^{+}$, respectively. This is in very strong contrast to the picture of BBFs as the main mass carrier in the plasma sheet (Angelopoulos et al., 1994, 1999).

We have used a somewhat more conservative method than what Angelopoulos et al. $(1992,1994)$ did in order to identify BBFs. They also considered segments with ion flows $>100 \mathrm{~km} \mathrm{~s}^{-1}$, but with at least one sample exceeding $400 \mathrm{~km} \mathrm{~s}^{-1}$. However, the largest difference is that Angelopoulos et al. $(1992,1994)$ considered two or more consecutive high-flow events as one if the time difference between the two events is less than $10 \mathrm{~min}$. This will for certain include a significant number of low-velocity data that are not included in the BBFs as defined and described in the paragraph above. If we use the same constraints for BBFs as Angelopoulos et al. (1992) we obtain a $\mathrm{H}^{+}$transport by BBFs corresponding to $10 \%$ of the total transport. This is still at least a factor of 5 smaller than suggested by Angelopoulos et al. (1994), and might be due to the fact that we investigate a much larger region, whereas they considered only the very inner central plasma sheet; we could, however, not see any significantly higher BBF occurrence rate in the central parts. The result is obviously dependent on the BBF selection criteria and it is the largest factor in our different results. Moreover, De Spiegeleer et al. (2017) investigated plasma sheet flows with oscillatory motions and concluded that BBFs or any other types of high-speed flows should not be defined for velocities smaller than $200 \mathrm{~km} \mathrm{~s}^{-1}$ in order not to include these oscillatory motions. This will put an even more limited constraint on our definition of BBFs and consequently lower their contribution to the total ion transport.

In our analysis of ion transport as a function of flow velocity $v_{x}$, we noted that lower velocities contributed significantly more than the higher flows, both for $\mathrm{H}^{+}$and $\mathrm{O}^{+}$, consistent with the low ion transport associated with BBFs as discussed above. The contributions to the total transport from flows with earthward velocities smaller than $100 \mathrm{~km} \mathrm{~s}^{-1}$ are 53 and $69 \%$ for $\mathrm{H}^{+}$and $\mathrm{O}^{+}$, respectively. The corresponding numbers for higher-velocity flows $(>200 \mathrm{~km}$ as suggested by De Spiegeleer et al., 2017), are 23 and 5\%. This would suggest, at any rate, that high-speed flows contribute significantly to the total $\mathrm{H}^{+}$transport, although they are not dominant. For $\mathrm{O}^{+}$, however, the contribution from the high-speed flows becomes much smaller and less important.

\section{Conclusions}

We have quantified the transports of $\mathrm{H}^{+}$and $\mathrm{O}^{+}$in the nearEarth plasma sheet $\left(-20<X_{\mathrm{GSM}}<-10 R_{\mathrm{E}},\left|Z_{\mathrm{GSM}}\right|<\right.$
$7 R_{\mathrm{E}}$ ), and the net transport for both species is earthward: for $\mathrm{H}^{+}$it is of the same order as the observed polar region outflow $\left(\sim 10^{26} \mathrm{~s}^{-1}\right)$, whereas it is $\sim 10^{24} \mathrm{~s}^{-1}$ for $\mathrm{O}^{+}, 1$ order of magnitude smaller than the polar region $\mathrm{O}^{+}$outflow. This shows that a majority of the ionospheric $\mathrm{O}^{+}$will escape into the solar wind via open magnetic field lines across the magnetopause rather than convect to the plasma sheet. The similar $\mathrm{H}^{+}$outflow and return flow indicate, however, that there is a more stable budget of $\mathrm{H}^{+}$in the magnetosphere.

The plasma sheet can be separated into the central plasma sheet and the outer plasma sheet (in or near the plasma sheet boundary layer), and the strongest earthward flows are in the central plasma sheet. The tailward flows are about the same in both regions for $\mathrm{H}^{+}$and $\mathrm{O}^{+}$, respectively. Due to the lower earthward ion flux in the outer plasma region the net $\mathrm{O}^{+}$ transport becomes tailward $\left(\sim 10^{24} \mathrm{~s}^{-1}\right)$ in the outer plasma sheet, as opposed to the central plasma sheet. For $\mathrm{H}^{+}$the net flux is earthward in both the central and outer plasma sheet.

The low-velocity flows $\left(<100 \mathrm{~km} \mathrm{~s}^{-1}\right)$ dominate the total ion transport, both tailward and earthward and both in the central and in the outer plasma sheet. This is most profound in the $\mathrm{O}^{+}$transport, where almost $70 \%$ of the total earthward transport comes from low-velocity flows. For $\mathrm{H}^{+}$the corresponding number is about $50 \%$. The most important factor in the ion transport for a certain velocity flow is the occurrence rate, such that fast flows $\left(>200 \mathrm{~km} \mathrm{~s}^{-1}\right)$ are relatively uncommon compared to lower velocity flows, and this is especially true for $\mathrm{O}^{+}$. The results suggest that BBFs are not dominant as contributors to the total $\mathrm{H}^{+}$transport. The contribution from $\mathrm{O}^{+}$associated with the $\mathrm{H}^{+}$BBFs to the total $\mathrm{O}^{+}$transport is very small and negligible.

Data availability. All Cluster data are freely accessible and retrieved from the Cluster Science Archive (https://www.cosmos.esa. int/web/csa) (ESA, 2017).

Competing interests. The authors declare that they have no conflict of interest.

Acknowledgements. The Swedish National Space Board, the Graduate School of Space Technology, and the Swedish Institute of Space Physics financed this study. The Cluster CODIF instrument team provided the necessary data, which can be freely retrieved from the Cluster Science Archive.

The topical editor, Christopher Owen, thanks Jasmine Sandhu and one anonymous referee for help in evaluating this paper. 


\section{References}

Abe, T., Watanabe, S., Whalen, B., Yau, A. W., and Sagawa, E.: Observations of polar wind and thermal ion outflow by Akebono/SMS, J. Geomagn. Geoelectr., 48, 319-325, https://doi.org/10.5636/jgg.48.319, 1996.

André, M. and Cully, C. M.: Low-energy ions: A previously hidden solar system particle population, Geophys. Res. Lett., 39, L03101, https://doi.org/10.1029/2011GL050242, 2012.

Angelopoulos, V., Baumjohann, W., Kennel, C. F., Coroniti, F. V., Kivelson, M. G., Pellat, R., Walker, R. J., Lühr, H., and Paschmann, G.: Bursty bulk flows in the inner central plasma sheet, J. Geophys. Res., 97, 4027-4039, https://doi.org/10.1029/91JA02701, 1992.

Angelopoulos, V., Kennel, C. F., Coroniti, F. V., Pellat, R., Kivelson, M. G., Walker, R. J., Russell, C. T., Baumjohann, W., Feldman, W. C., and Gosling, J. T.: Statistical characteristics of bursty bulk flow events, J. Geophys. Res., 97, 21257-21280, https://doi.org/10.1029/94JA01263, 1994.

Angelopoulos, V., Mozer, F. S., Lin, R. P., Mukai, T., Tsuruda, K., Lepping, R., and Baumjohann, W.: Comment on "Geotail survey of ion flow in the plasma sheet: Observations between 10 and $50 R_{\mathrm{E}}$ ” by W. R. Paterson et al., J. Geophys. Res., 104, 1752117525, https://doi.org/10.1029/1999JA900198, 1999.

Axford, W.: The polar wind and the terrestrial helium budget, J. Geophys. Res., 73, 6855-6859, https://doi.org/10.1029/JA073i021p06855, 1968.

Baumjohann, W., Paschmann, G., Sckopke, N., Cattell, C. A., and Carlson, C. W.: Average ion moments in the plasma sheet boundary layer, J. Geophys. Res., 93, 11507-11520, https://doi.org/10.1029/JA093iA10p11507, 1988.

Baumjohann, W., Paschmann, G., and Cattell, C. A.: Average plasma properties in the central plasma sheet, J. Geophys. Res., 94, 6597-6606, https://doi.org/10.1029/JA094iA06p06597, 1989.

Baumjohann, W., Paschmann, G., and Lühr, H.: Characteristics of high-speed ion flows in the plasma sheet, J. Geophys. Res., 95, 3801-3809, https://doi.org/10.1029/JA095iA04p03801, 1990.

Chappell, C. R., Giles, B. L., Moore, T. E., Delcourt, D. C., Craven, P. D., and Chandler, M. O.: The adequacy of the ionospheric source in supplying magnetospheric plasma, J. Atmos. Sol.-Terr. Phy., 62, 421-436, https://doi.org/10.1016/S13646826(00)00021-3, 2000.

Cully, C. M., Donovan, E. F., Yau, A. W., and Opgenoorth, H. J.: Supply of thermal ionospheric ions to the central plasma sheet, J. Geophys. Res.-Space, 108, 1092, https://doi.org/10.1029/2002JA009457, 2003.

De Spiegeleer, A., Hamrin, M., Pitkänen, T., Volwerk, M., Mann, I., Nilsson, H., Norqvist, P., Andersson, L., and Vaverka, J.: Low frequency oscillatory flow signatures and high-speed flows in the Earth's magnetotail, J. Geophys. Res., 122, https://doi.org/10.1002/2017JA024076, 2017.

Dubouloz, N., Bouhram, M., Senior, C., Delcourt, D., Malingre, M., and Sauvaud, J.-A.: Spatial structure of the cusp/cleft ion fountain: A case study using a magnetic conjugacy between Interball AP and a pair of SuperDARN radars, J. Geophys. Res., 106, 261274, https://doi.org/10.1029/2000JA000142, 2001.

Ejiri, M., Hoffman, R. A., and Smith, P. H.: Energetic particle penetrations into the inner magnetosphere, J. Geophys. Res., 85, 653663, https://doi.org/10.1029/JA085iA02p00653, 1980.
Engwall, E., Eriksson, A. I., André, M., Dandouras, I., Paschmann, G., Quinn, J., and Torkar, K.: Low-energy (order $10 \mathrm{eV}$ ) ion flow in the magnetotail lobes inferred from spacecraft wake observations, Geophys. Res. Lett., 33, L06110, https://doi.org/10.1029/2005GL025179, 2006.

Engwall, E., Eriksson, A. I., Cully, C. M., André, M., Puhl-Quinn, P. A., Vaith, H., and Torbert, R.: Survey of cold ionospheric outflows in the magnetotail, Ann. Geophys., 27, 3185-3201, https://doi.org/10.5194/angeo-27-3185-2009, 2009a.

Engwall, E., Eriksson, A. I., Cully, C. M., André, M., Torbert, R., and Vaith, H.: Earth's ionospheric outflow dominated by hidden cold plasma, Nat. Geosci., 2, 24-27, https://doi.org/10.1038/ngeo387, 2009b.

ESA: Cluster data, available at: https://www.cosmos.esa.int/web/ csa, last access: 30 June 2017.

Escoubet, C. P., Fehringer, M., and Goldstein, M.: Introduction The Cluster mission, Ann. Geophys., 19, 1197-1200, https://doi.org/10.5194/angeo-19-1197-2001, 2001.

Haaland, S., Eriksson, A. I., Engwall, E., Lybekk, B., Nilsson, H., Pedersen, A., Svenes, K., Förster, M., Li, K., Johnsen, C., and Østgaard, N.: Estimating the capture and loss of cold plasma from ionospheric outflow, J. Geophys. Res., 117, A07311, https://doi.org/10.1029/2012JA017679, 2012.

Haaland, S., Eriksson, A. I., André, M., Maes, L., Baddeley, L., Barakat, A., Chappell, R., Eccles, V., Johnsen, C., Lybekk, B., Pedersen, A., Schunk, R., and Welling, D.: Estimation of cold plasma outflow during geomagnetic storms, J. Geophys. Res., 120, 10622-10639, https://doi.org/10.1002/2015JA021810, 2015.

Hamrin, M., Norqvist, P., Marghitu, O., Buchert, S., Klecker, B., Kistler, L. M., and Dandouras, I.: Occurrence and location of concentrated load and generator regions observed by Cluster in the plasma sheet, Ann. Geophys., 27, 4131-4146, https://doi.org/10.5194/angeo-27-4131-2009, 2009.

Hamrin, M., Pitkänen, T., Norqvist, P., Karlsson, T., Nilsson, H., André, M., Buchert, S., Vaivads, A., Marghitu, O., Klecker, B., Kistler, L. M., and Dandouras, I.: Evidence for the braking of flow bursts as they propagate toward the Earth, J. Geophys. Res., 119, 9004-9018, https://doi.org/10.1002/2014JA020285, 2014.

Karlsson, T., Hamrin, M., Nilsson, H., Kullen, A., and Pitkänen, T.: Magnetic forces associated with bursty bulk flows in Earth's magnetotail, Geophys. Res. Lett., 42, 3122-3128, https://doi.org/10.1002/2015GL063999, 2015.

Kistler, L. M., Mouikis, C. G., Cao, X., Frey, H., Klecker, B., Dandouras, I., Korth, A., Marcucci, M. F., Lundin, R., McCarthy, M., Friedel, R., and Lucek, E.: Ion composition and pressure changes in storm time and nonstorm substorms in the vicinity of the near-Earth neutral line, J. Geophys. Res., 111, A11222, https://doi.org/10.1029/2006JA011939, 2006.

Liao, J., Kistler, L. M., Mouikis, C. G., Klecker, B., Dandouras, I., and Zhang, J.-C.: Statistical study of $\mathrm{O}^{+}$transport from the cusp to the lobes with Cluster CODIF data, J. Geophys. Res., 115, A00J15, https://doi.org/10.1029/2010JA015613, 2010.

Liao, J., Kistler, L. M., Mouikis, C. G., Klecker, B., and Dandouras, I.: Solar cycle dependence of the cusp $\mathrm{O}^{+}$access to the near-Earth magnetotail, J. Geophys. Res., 117, A10220, https://doi.org/10.1029/2012JA017819, 2012.

Liao, J., Kistler, L. M., Mouikis, C. G., Klecker, B., and Dandouras, I.: Acceleration of $\mathrm{O}^{+}$from the cusp to the 
plasma sheet, J. Geophys. Res.-Space, 120, 1022-1034, https://doi.org/10.1002/2014JA020341, 2015.

Lui, A. T. Y., Eastman, T. E., William, D. J., and Frank, L. A.: Observations of ion streaming during substorms, J. Geophys. Res., 88, 7753-7764, https://doi.org/10.1029/JA088iA10p07753, 1983.

Nilsson, H.: Heavy ion energization, transport, and loss in the Earth's magnetosphere, in: The Dynamic Magnetosphere, edited by: Liu, W. and Fujimoto, M., IAGA, Springer, Dordrecht, https://doi.org/10.1007/978-94-007-0501-2_17, 2011.

Nilsson, H., Waara, M., Arvelius, S., Marghitu, O., Bouhram, M., Hobara, Y., Yamauchi, M., Lundin, R., Rème, H., Sauvaud, J.-A., Dandouras, I., Balogh, A., Kistler, L. M., Klecker, B., Carlson, C. W., Bavassano-Cattaneo, M. B., and Korth, A.: Characteristics of high altitude oxygen ion energization and outflow as observed by Cluster: a statistical study, Ann. Geophys., 24, 1099-1112, https://doi.org/10.5194/angeo-24-1099-2006, 2006.

Nilsson, H., Engwall, E., Eriksson, A., Puhl-Quinn, P. A., and Arvelius, S.: Centrifugal acceleration in the magnetotail lobes, Ann. Geophys., 28, 569-576, https://doi.org/10.5194/angeo-28569-2010, 2010.

Nilsson, H., Barghouthi, I. A., Slapak, R., Eriksson, A., and André, M.: Hot and cold ion outflow: spatial distribution of ion heating, J. Geophys. Res., 117, A11201, https://doi.org/10.1029/2012JA017974, 2012.

Nilsson, H., Hamrin, M., Pitkänen, T., Karlsson, T., Slapak, R., Andersson, L., Gunell, H., Schillings, A., and Vaivads, A.: Oxygen ion response to proton bursty bulk flows, J. Geophys. Res., 121, 7535-7546, https://doi.org/10.1002/2016JA022498, 2016.

Orsini, S., Candidi, M., Stokholm, M., and Balsiger, H.: Injection of ionospheric ions into the plasma sheet, J. Geophys. Res., 95, 7915-7928, https://doi.org/10.1029/JA095iA06p07915, 1990.

Paterson, W. R., Frank, L. A., Kokubun, S., and Yamamoto, T.: Geotail survey of ion flow in the plasma sheet: Observations between 10 and $50 R_{\mathrm{E}}$, J. Geophys. Res., 103, 11811-11825, https://doi.org/10.1029/97JA02881, 1998.

Pollock, C. J., Chandler, M. O., Moore, T. E., Waite Jr., J. H., Chappell, C. R., and Gurnett, D. A.: A survey of upwelling ion event characteristics, J. Geophys. Res., 95, 18969-18980, https://doi.org/10.1029/JA095iA11p18969, 1990.

Rème, H., Aoustin, C., Bosqued, J. M., Dandouras, I., Lavraud, B., Sauvaud, J. A., Barthe, A., Bouyssou, J., Camus, Th., Coeur-Joly, O., Cros, A., Cuvilo, J., Ducay, F., Garbarowitz, Y., Medale, J. L., Penou, E., Perrier, H., Romefort, D., Rouzaud, J., Vallat, C., Alcaydé, D., Jacquey, C., Mazelle, C., d'Uston, C., Möbius, E., Kistler, L. M., Crocker, K., Granoff, M., Mouikis, C., Popecki, M., Vosbury, M., Klecker, B., Hovestadt, D., Kucharek, H., Kuenneth, E., Paschmann, G., Scholer, M., Sckopke, N., Seidenschwang, E., Carlson, C. W., Curtis, D. W., Ingraham, C., Lin, R. P., McFadden, J. P., Parks, G. K., Phan, T., Formisano, V., Amata, E., Bavassano-Cattaneo, M. B., Baldetti, P., Bruno, R., Chionchio, G., Di Lellis, A., Marcucci, M. F., Pallocchia, G., Korth, A., Daly, P. W., Graeve, B., Rosenbauer, H., Vasyliunas, V., McCarthy, M., Wilber, M., Eliasson, L., Lundin, R., Olsen, S., Shelley, E. G., Fuselier, S., Ghielmetti, A. G., Lennartsson, W., Escoubet, C. P., Balsiger, H., Friedel, R., Cao, J.-B., Kovrazhkin, R. A., Papamastorakis, I., Pellat, R., Scudder, J., and Sonnerup, B.: First multispacecraft ion measurements in and near the Earth's magnetosphere with the identical Cluster ion spectrometry (CIS) experiment, Ann. Geophys., 19, 1303-1354, https://doi.org/10.5194/angeo-19-1303-2001, 2001.

Savin, S., Budnik, E., Nozdrachev, M., and Romanov, V.: On the plasma turbulence ant at the polar cusp outer border, Chekhoslovak J. Phys., 49, 679-693, https://doi.org/10.1002/2016JA022498, 1999.

Seki, K., Hirahara, M., Terasawa, T., Mukai, T., Saito, Y., Machida, S., Yamamoto, T., and Kokubun, S.: Statistical properties and possible supply mechanisms of tailward cold $\mathrm{O}^{+}$beams in the lobe/mantle regions, J. Geophys. Res., 103, 4477-4489, https://doi.org/10.1029/97JA02137, 1998.

Seki, K., Elphic, R. C., Hirahara, M., Terasawa, T., and Mukai, T.: On atmospheric loss of oxygen ions from Earth through magnetospheric processes, Science, 291, 1939-1941, 2001.

Seki, K., Hirahara, M., Hoshino, M., Terasawa, T., Elphic, R. C., Saitok, Y., Mukaik, T., Hayakawak, H., Kojima, H., and Matsumoto, H.: Cold ions in the hot plasma sheet of Earth's magnetotail, Nature, 422(6932), 589-592, https://doi.org/10.1038/nature01502, 2003.

Sharma, A. S., Nakamura, R., Runov, A., Grigorenko, E. E., Hasegawa, H., Hoshino, M., Louarn, P., Owen, C. J., Petrukovich, A., Sauvaud, J.-A., Semenov, V. S., Sergeev, V. A., Slavin, J. A., Sonnerup, B. U. Ö., Zelenyi, L. M., Fruit, G., Haaland, S., Malova, H., and Snekvik, K.: Transient and localized processes in the magnetotail: a review, Ann. Geophys., 26, 955 1006, https://doi.org/10.5194/angeo-26-955-2008, 2008.

Shelley, E. G., Peterson, W. K., Ghielmetti, A. G., and Geiss, J.: The polar ionosphere as a source of energetic magnetospheric plasma, Geophys. Res. Lett., 9, 941-944, https://doi.org/10.1029/GL009i009p00941, 1982.

Slapak, R., Nilsson, H., and Westerberg, L. G.: A statistical study on $\mathrm{O}^{+}$flux in the dayside magnetosheath, Ann. Geophys., 31, 1005-1010, https://doi.org/10.5194/angeo-31-1005-2013, 2013.

Slapak, R., Nilsson, H., Westerberg, L. G., and Larsson, R.: $\mathrm{O}^{+}$transport in the dayside magnetosheath and its dependence on the IMF direction, Ann. Geophys., 33, 301-307, https://doi.org/10.5194/angeo-33-301-2015, 2015.

Walker, R. J., Richard, R. L., and Ashour-Abdalla, M.: The entry of solar wind ions into the magnetosphere, in: Physics of the magnetopause, American Geophysical Union, 90, 311-319, https://doi.org/10.1029/GM090p0311, 2013.

Yau, A. W. and André, M.: Sources of ion outflow in the high latitude ionosphere, Space Sci. Rev., 80, 1-25, https://doi.org/10.1023/A:1004947203046, 1997. 